\title{
2020 Annual Trends and Outlook Report Sustaining Africa's Agrifood System Transformation: The Role of Public Policies
}

\author{
Edited by Danielle Resnick, Xinshen Diao, and Getaw Tadesse
}

November 2020

Arica achieved the fastest growth rate in agriculture over the last two decades. This performance needs to be sustained and accelerated if the sector is to play its critical role in helping meet the continent's development goals, including creating decent jobs for youth, nourishing growing cities with healthy foods, and catalyzing domestic revenue mobilization for public goods and services. This calls for continued improvement of the sector's governance, in particular policies conducive to meeting the current and future needs of Africa's rapidly transforming agrifood value chains. The centrality of productive agriculture and robust food supply chains, as well as related policies and institutions, to achieving the resilience and prosperity goals of the African Union's (AU) Agenda 2063 is highlighted by the disruptive ramifications of the COVID-19 pandemic.

The 2020 Annual Trends and Outlook Report (ATOR) therefore focuses on a set of comprehensive and complementary policies required to transform African agrifood systems to meet their potential. The report starts with (1) in-depth review of the evolution of agricultural sector policies over the last five decades; followed by a systematic analysis of (2) traditional input constraints on agricultural productivity; (3) policies needed to bolster competitiveness along value chains; and (4) factors that shape the broader enabling environment needed for agrifood system transformation. Five major lessons emerge.

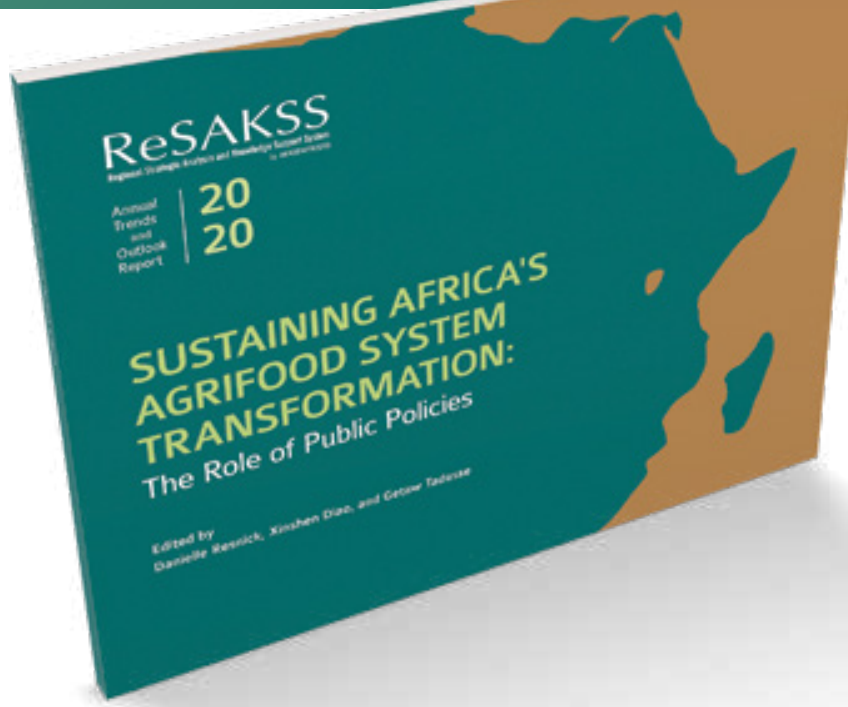

\section{Learn from Past Mistakes and Achievements}

How do contemporary agricultural sector policies compare with their historical counterparts, and to what degree can past mistakes be avoided as a new generation of policy leaders emerges in Africa? Such reflection is necessary to solidify important achievements of the last decade, including a growing increase in Africa's share of global agricultural gross domestic product (GDP) and continued reduction in the anti-agriculture fiscal biases that prevailed in prior decades.

A new generation of leaders and the lack of sufficient institutional memory in the context of more open, pluralistic political systems along with strong populist pressures pose a risk of returning to failed policies of the 1970s and 1980s, when strong government intervention, distorted trade regimes, and macroeconomic imbalances prevailed. In the last five years, there has been renewed government involvement in input supply chains in many countries, including price setting, restrictions on private traders, and mandated harvest dates. Export and import bans have been promoted as a way to ensure adequate domestic resources for agro-industrial 
initiatives. Although countries made considerable effort in earlier years to meet the Comprehensive Africa Agriculture Development Programme (CAADP) commitments of achieving 6 percent agricultural growth and allocating 10 percent of the national budget to agriculture, there are worrying signs that annual public expenditure for agriculture is stagnating or even declining for the first time in two decades.

Learning has occurred as a result of refining policy choices and implementation over time. For example, new agricultural input subsidy programs were developed in response to the 2006 Abuja Fertilizer Summit and the food price crisis of 2007-2008. In 2014, the Malabo Declaration pointed to the need to make these programs "smarter," and increasingly, such programs have responded by including seed along with fertilizer, incorporating fertilizers better-targeted to local soil quality, and integrating information and communications technology (ICT) innovations (such as e-vouchers) to improve beneficiary targeting. These programs will also need to improve climate resilience and nutritional diversity (rather than just supporting cereal crops), without sacrificing agricultural R\&D spending to support subsidy expenditures. Indeed, public agricultural research spending as a share of agricultural GDP remains far below the 1 percent level recommended by the AU.

Similarly, increased farming intensity and the rise of mediumto large-scale farmers have expanded the demand for mechanization. As in the past, many African countries are relying on some form of government subsidy to finance mechanization centers or access to tractors. Due to evidence about challenges to such state-led approaches, including lack of profitability and low demand, some reforms have followed. In Ghana, for example, the government has provided more variety in tractor offerings based on farmer needs and incorporated maintenance and training initiatives into its mechanization program. These and other lessons will be valuable to the implementation of the AU's framework for Sustainable Agricultural Mechanization in Africa.

\section{Adopt a Holistic Agenda}

The need for holistic agendas is emphasized through chapters that collectively span the entire agrifood system and which examine the individual subcomponents of agrifood systems.

\section{Agricultural Inputs}

The seed and fertilizer sectors are good examples. Increasing availability of higher-quality, higher-yielding seed varieties requires attention to: (1) improving countries' access to genetic material needed for breeding programs that meet local needs; (2) investing in breeding methods that speed the development of new cultivars; (3) ensuring that regulatory systems do not deter testing, registration, or release of new cultivars; and (4) creating market conditions that allow farmers to generate sufficient returns to their investment. To enhance productivity, increased distribution of fertilizer requires concurrent investments in agronomy programs, irrigation development, soil testing, and extension services, as well as greater encouragement of private sector participation in fertilizer markets. Beyond this are a host of supply chain considerations dealing particularly with the need to reduce the cost of operations along the various segments.
Skills Development

Agricultural technical and vocational education and training (ATVET) for farmers is another prime area where a comprehensive array of interventions is needed. Vocational training is essential to transform farmers into entrepreneurs and to attract underemployed youth into the sector. In general, ATVET has been woefully underprovided in Africa or typically focuses on the farm level and on agricultural practices. This ATOR suggests that successful ATVET should also target support professions across the entire value chain, including machine technicians for servicing tractors and electricians to ensure functioning agro-processing operations. Cross-cutting training in finance, accounting, insurance, and ICT are also needed for farmers to operate more as competitive businesses.

\section{Digitalization and ICT}

More broadly, ICT and digital technologies are viewed as key drivers of innovation and productivity for agrifood systems and have received renewed attention during the COVID-19 pandemic. Mobile applications and e-commerce platforms can connect farmers, traders, and consumers; likewise, drones and satellite data can improve national agricultural statistics and planning. As many African countries develop their national ICT polices and strategies, further attention is needed to Internet connectivity, improved digital literacy, regulations related to digital privacy, and network platforms and innovation hubs. Domestic financing of digitalization, delinked from donor priorities, is also essential to ensure sustainability even as donor preferences evolve.

\section{Agricultural Trade}

Enhanced agricultural trade is essential for agrifood system transformation, and over the last two decades global value chains have expanded rapidly. African participation is growing, reflected in increased penetration of export markets in emerging economies and a rising share of processed and semi-processed products, which now account for the largest share in exports. Interestingly, African exporters encounter fewer restrictions in global markets than in intracontinental markets, due to many internal regulatory and administrative barriers that raise the cost of trading for African enterprises. The imminent implementation of the African Continental Free Trade Area will expand market opportunities, but will not reduce the need for a broader array of interventions. Indeed, lengthy customs procedures, poor transport and communications logistics, insufficient adoption of international sanitary and phytosanitary standards, and general policy volatility must be addressed to enhance the region's export performance in regional and global markets.

\section{Embrace Nuance for More Effective Policy Targeting}

The diversity of farmers and consumers within the agrifood system implies a clear need to avoid uniform policy interventions in any segment of the system. Smallholders have different requirements than their commercial counterparts; formal small and medium-size food enterprises face different portfolios of taxes, savings, and capital needs than informal retail businesses; and middle-class consumers often can afford healthier and safer food than their poorer compatriots. 
Thus, policies in each domain of the agrifood system also need to be targeted properly.

\section{Irrigation and Water Management}

On the farm, Africa's vast biophysical differences require that irrigation interventions be appropriately differentiated. The $\mathrm{AU}$ identifies four different pathways for improving irrigation and water management. These range from large-scale irrigation development and modernization to farmer-led irrigation development to improved water control and watershed management in rainfed environments, as well as wastewater recovery and reuse. Pursuing these different pathways, however, requires attention to trade-offs with other key commitments made by African governments, notably the UN Sustainable Development Goals. For instance, environmental goals can be jeopardized by the spread of more affordable irrigation technology, especially if it allows for more intensive use of fertilizer and pesticide chemicals that contribute to water pollution. Addressing these trade-offs will require new data tools to help governments measure and monitor irrigation, agricultural water pollution management systems, investments in affordable clean energy, strengthened national and subnational water institutions and frameworks, and irrigation projects that foster the cultivation of nutrient-dense crops.

\section{Producer Organizations and Collective Action}

The institutional organization of producers is likewise diverse. Producer organizations, which are membership-based organizations or federations of organizations with elected leaders accountable to their constituents, have long been viewed as conducive to helping farmers access inputs and share information. However, they are not equivalent in structure. Some are commodity-specific organizations that defend their members' control of a commodity chain, some are advocacy groups that represent producers' interests, others are associations of users of natural resources, and still others are multipurpose organizations that respond to the needs of their members in the absence of sufficient public goods and services. Technical efficiency is higher for those involved in a producer organization than for those who are not, and such efficiency is particularly strong for members of those organizations that have a board and make collective decisions via a general assembly. Therefore, although governments should encourage such organizations, they should also recognize that particular governance modalities appear more conducive than others to better efficacy.

\section{Agricultural Processing and}

\section{Midstream Value Chains}

Off the farm, local food markets offer many opportunities to support enterprise creation and agro-industrialization. Policies to boost processing and midchain agrifood segments are at the heart of enhancing economic growth and nutrition outcomes. Indeed, value chain development emerged from the 2014 Malabo Declaration as one of the key areas of CAADP. Yet Africa's agro-processors are bifurcated, consisting, on the one hand, of millions of small enterprises that face barriers to technology, skills, financing, and markets, and on the other hand, of large businesses that dominate agro-industrial zones. Moreover, some value chains operating in local and regional markets face high costs and rapidly changing diet preferences. In contrast, those aimed at global markets, including markets for coffee, fruits, and vegetables, may face stronger competition and more demanding consumers. Taking these considerations into account, contributors to the 2020 ATOR delineate six different bundles of policy priorities, revolving around training-related, technological, regulatory, and institutional interventions, while also considering gender implications of these different policies.

\section{Food Safety Risks}

On the consumer side, Africa's agrifood systems cannot expand, either globally or domestically, without greater congruence with food safety standards. Due to urbanization and income growth, consumer demand is increasing for animal products, fruits and vegetables, and processed foods. Yet the safety of such foods, and the capacity to enforce food safety standards, remains woefully insufficient. Identifying food safety priorities requires African governments to consider multiple dimensions, including how a country's food system is evolving and whether it has the capacity for food safety regulatory oversight and enforcement. For example, some countries have a "traditional" food system with minimal dietary diversity and weak capacity, whereas others have more diverse food systems with good management of food safety risks and stable consumer demand. Many of Africa's lower-middle-income countries fall between these two extremes, with rapidly changing diets and health risks but lagging capacity and incentives for food safety regulation. Moreover, the food industry structure varies substantially in the region, with modern retail industries (supermarkets, e-commerce operations, convenience stores) and informal retail markets (wet and open-air markets), as well as a range of out-of-home eating options. Each of these modalities presents its own food safety risks and priorities. To address food safety weaknesses, governments should balance investments in laboratories, infrastructure, and processing facilities with support for improved human capital and awareness raising for behavioral change.

\section{Invest in Accountable Policy Systems}

\section{Mutual Accountability}

Taken together, this ATOR's emphasis on learning from past mistakes and achievements, adopting holistic responses, and embracing nuance requires robust policymaking systems that are inclusive, transparent, and accountable. In this regard, the AU's promotion of mutual accountability will continue to be a necessary guiding principle for the region to meet its transformation goals. Mutual accountability is a process by which two or more partners agree to be held jointly responsible for commitments they have willingly made to each other. The principle was adopted by the AU in 2002 and into CAADP in 2003. It has been operationalized through activities that promote dialogue, benchmarking, and peer learning within the agriculture sector. Since the 2014 Malabo CAADP summit, the AU has further formalized the concept through agricultural joint sector reviews whereby both state and nonstate actors assess progress. Furthermore, African leaders have now held two continental biennial reviews to assess their progress, using African Agriculture Transformation Scorecards to track performance against the Malabo target milestones.

Contributions to this ATOR show that after the first biennial review, some countries made notable improvements in data collection, budget allocations, and monitoring and evaluation 
systems. In addition, countries that have conducted a joint sector review are found to have higher levels of public agricultural expenditures. In turn, these expenditures have had a positive impact on labor and land productivity, both of which are critical for agricultural transformation. As countries consider a broader agrifood systems agenda that builds on achievements of the agricultural sector but also expands well beyond that sector, this ATOR reaffirms that the process of making quantifiable commitments and subjecting those commitments to public scrutiny is important for avoiding myopic policy planning.

\section{Anticipate Risks and Plan Accordingly}

The COVID-19 pandemic illustrates vividly that even wellintended policies can be undermined by unexpected shocks. Travel bans as well as quarantines on transporters held up the import and distribution of critical farm inputs. Curfews and lockdowns worsened consumer access to food. Crowded informal markets with poor water and sanitation infrastructure had to be closed, undermining small-scale retailers' already meager incomes. In parts of the continent, the pandemic exacerbated other stresses encountered by farmers, including fall armyworm and the devastating locust plague in East Africa. All of these shocks transcend boundaries, and mitigation will necessitate cross-national coordination.

\section{Macroeconomic Policies}

Such shocks have also contributed to depressed economic growth in Africa. In some countries, COVID-19 has worsened already worrying levels of external debt that resurfaced after 2010. The 2008-2009 global financial crisis led to an expansion of dollar- and euro-denominated sovereign bonds for African countries, offering access to increased borrowing at higher interest rates. With a subsequent contraction of commodity prices, debt services have ballooned and more than a dozen African countries are at risk of debt distress. Undoubtedly, these countries face increased fiscal constraints and will need to make stark decisions about priorities within the agricultural sector and the broader agrifood system. This ATOR therefore provides some evidence about the range of investments that could have sizable impacts.

\section{Political Economy}

At the same time, history shows that political economy challenges - specifically reconciling competing interests and overcoming ideational biases - can stymie the implementation of evidence-based policy recommendations. Political economy considerations can be most pronounced when resources are scarce, and therefore, certain groups are more likely to benefit than others. These issues, long present in African agricultural policy processes, likely explain some distortionary policies previously prominent in the region. This report, however, underlines new political economy risks that need to be considered. With an agrifood system agenda that spans the mandates of multiple ministries and both national and subnational governments, coordination mechanisms will be needed to promote collaboration across a range of government and private sector actors, and to mitigate bureaucratic competition over responsibilities and budgets. Consequently, it will be imperative to consider viable public sector reforms that can enable implementation of a complex transformation agenda.

Overall, African governments are operating under rapidly changing climatic and economic circumstances but remain firmly focused on meeting their national and regional development aspirations. By touching on the range of agrifood system issues identified by the $A U$ as priorities in recent years, the 2020 ATOR hopes to provide robust policy guidance to navigate the uncertain period ahead.

\section{About ReSAKSS}

Established in 2006 under the Comprehensive Africa Agriculture Development Programme (CAADP), the Regional Strategic Analysis and Knowledge Support System (ReSAKSS) supports efforts to promote evidence- and outcome-based policy planning and implementation. In particular, ReSAKSS provides data and related analytical and knowledge products to facilitate CAADP benchmarking, review, and mutual learning processes. AKADEMIYA2063 leads the work of ReSAKSS in partnership with the African Union Commission, the African Union Development Agency-NEPAD (AUDA-NEPAD), and leading regional economic communities (RECs).

ReSAKSS helps to inform CAADP through its flagship Annual Trends and Outlook Reports (ATORs). The Africawide ATOR, which serves as the official CAADP M\&E report, tracks progress on over 30 key CAADP indicators. Each year, the ATOR presents analysis on a feature topic of strategic importance to the CAADP agenda.

This synopsis is based on the peer-reviewed 2020 ReSAKSS Annual Trends and Outlook Report-Sustaining Africa's Agrifood System Transformation: The Role of Public Policies, edited by D. Resnick, X. Diao, and G. Tadesse. The full report is available for free download at https://doi.org/10.2499/9780896293946. www.resakss.org

\section{AKADEMIYA2063}

Kicukiro/Niboye KK 341 St 22

P.O. Box 1855

Kigali, Rwanda

Tel.: +221-77-761-73-02

Email: resakss@akademiya2063.org www.akademiya2063.org
International Food Policy Research Institute

1201 Eye Street, NW

Washington, DC 20005 USA

Tel.: + 1-202-862-5600

Fax: $+1-202-862-5606$

Email: ifpri@cgiar.org

www.ifpri.org | www.ifpri.info
DOI:https://doi.org/10.2499/9780896293953

C 2020 International Food Policy Research Institute (IFPRI). This publication is licensed for use under a Creative Commons Attribution 4.0 International License (CC BY 4.0). 